\title{
Molecular and Recombinational Characterization of Begomovirus Infecting an Ornamental Plant Alternanthera sessilis: A New Host of Tomato Leaf Curl Kerala Virus Reported in India
}

\author{
Avinash Marwal, Anurag Kumar Sahu, Rajneesh Prajapat, Devendra Kumar Choudhary and \\ Rajarshi Kumar Gaur \\ Department of Science, Faculty of Arts, Science and Commerce, Mody Institute of Technology and Science, \\ Lakshmangarh, Sikar-332311, Rajasthan, India
}

\begin{abstract}
Begomovirus associated symptoms were observed in Alternanthera sessilis ornamentals growing in the gardens of Lakshmangarh, Rajasthan (India). Amplification of a PCR product was found up to the expected size ( $\sim 550 \mathrm{bp}$ ). The PCR product was cloned and sequenced and it was utilized for molecular characterization. Recombination plays a key role in the evolution of begomovirus and may be contributing to the emergence of new species. With the development of computational recombination detection tools and an increasing number of available genome sequences, many studies have reported evidence of recombination. Various recombination events suggested that interspecific recombination has resulted in significant diversity among begomovirus. Sequence analysis showed closed similarity (98\%) with Tomato leaf curl Kerala virus, substantiating its new host as Alternanthera sessilis.
\end{abstract}

Key words: Begomovirus, Alternanthera sessilis, ornamental, recombination, tomato leaf curl Kerala virus, new host

Science International, 1 (3): 51-56, 2013

\section{INTRODUCTION}

Alternanthera sessilis is an ornamental plant, also known as dwarf copperleaf. It belongs to the family Amaranthaceae. It occurs in both wetlands and uplands and can grow on a variety of soil types. For the propagation of the plant, it is generally spread by rooting at stem nodes and by seeds, which are wind and water-dispersed ${ }^{1}$. The young leaves is very rich in iron, vitamin A and dietary fiber especially the tip portion are eaten as vegetable in the Southeast Asian countries, thus the plant is an immense remedy for the anaemic patients in rural areas. Moreover the carotene rich content of the $A$. sessilis plant helps in curing night blindness. The plant enhances the secretion of milk in new mothers ${ }^{2}$ and it is used as a remedy against intestinal cramps, diarrhoea and dysentery (intestinal dis-order) and externally as a cooling agent to treat fever. Naples $^{2}$ also reported that $A$. sessilis is used internally against intestinal inflammation, externally to treat wounds, to treat hepatitis, tight chest, bronchitis, asthma, lung troubles, to stop bleeding and as a hair tonic. Geminiviruses are characterized by circular single stranded DNA (ssDNA) genomes encapsidated in twinned quasi isometric particles of about $18 \times 30 \mathrm{~nm}^{3}$. The Geminiviridae family has been divided into four genera based on

Corresponding Author: Rajarshi Kumar Gaur, Department of Science, Faculty of Arts, Science and Commerce, Mody Institute of Technology and Science, Lakshmangarh, Sikar-332311, Rajasthan, India Tel: +919352911723 Fax: +911573225041 genome organization and host range: Mastrevirus, Curtovirus, Topocuvirus and Begomovirus 4 . Begomovirus is the only genus of the Geminiviridae have bipartite genome with virus genes resident on two different circular ssDNA molecules (DNA A, DNA B) each of about $2.6-2.8 \mathrm{~kb}^{5}$, or monopartite with all genes resident on one (DNA A-like) ssDNA of about $2.8 \mathrm{~kb}$. Begomovirus is one of the largest genus of the family Geminiviridae ${ }^{6}$ and the vector white fly (Bemisia tabaci) is prevalent in the tropical and subtropical regions of the world? ${ }^{7}$ Some monopartite begomoviruses are associated with betasatellites (DNA $\beta$ ), which require begomoviruses for replication, encapsidation, insect transmission and movement in plants ${ }^{8}$. Increasing knowledge about its epidemiology, sequence diversity and biodiversity is highly important in order to implement preventative strategies.

Recombination has played and continues to play, a pivotal role in geminiviral evolution and may be contributing to the emergence of new forms of Geminiviruses because the high frequency of mixed infections of Begomoviruses provides an opportunity for the emergence of new viruses arising from recombination among strains and/or species. In some cases, the recombinants exhibited a new pathogenic phenotype which is often more virulent than the parents ${ }^{10}$. Hence the object of this study is molecular, phylogenetic and in silico recombinational analysis of Begomovirus infecting an ornamental plant $A$. sessilis. 


\section{MATERIAL AND METHODS}

Samples collection and DNA extraction: Survey for the epidemiology of Begomovirus was carried out in 20102011. Begomovirus associated symptoms were observed in A. sessilis plants growing in garden fields of Lakshmangarh, Rajasthan (India). To investigate the possibility Total DNA was extracted from leaves of plants with and without symptoms using CTAB (Cetyl Trimethyl Ammonium Bromide) method ${ }^{11}$.

PCR amplification: PCR was performed using a pair of primers designed to the coat protein region of begomovirus $^{12}$. Forward primer sequence was GGRTTDGARGCATGHGTACATG (AC 1048) and reverse primer sequence was GCCYATRTAYAGRAAGCCMAG (AV 494). A typical PCR reaction contained about 100 ng DNA template, Taq 10x buffers (10 mM Tris- $\mathrm{HCl}, \mathrm{pH} 8.8,50 \mathrm{mM} \mathrm{KCl}$ and $1 \%[\mathrm{v} / \mathrm{v}]) 25 \mathrm{mM} \mathrm{MgCl}_{2}, 200 \mu \mathrm{M}$ of each dNTPs, 2 units of Taq DNA Polymerase, Nuclease free water and $10 \mathrm{pM}$ of each primer. The PCR thermal profile were pre-PCR denaturation at $94^{\circ} \mathrm{C}$ for $120 \mathrm{sec}$ followed by 35 cycles of denaturing at $94^{\circ} \mathrm{C}$ for $45 \mathrm{sec}$, annealing at $55^{\circ} \mathrm{C}$ for $60 \mathrm{sec}$ and extension at $72^{\circ} \mathrm{C}$ for $60 \mathrm{sec}$ and a final extension at $72^{\circ} \mathrm{C}$ for $5 \mathrm{~min}^{3}$.

Cloning, sequencing and Phylogenetic tree construction: PCR product of $\sim 550$ bp from infected A. sessilis samples was cloned and partially sequenced and has been deposited in NCBI GenBank having Accession No: JQ693140. Homology sequence search was carried out through BLASTn using which Phylogenetic and molecular evolutionary analyses were conducted using MEGA version $4.0^{14}$.

RDP: To detect the possibility of recombination in Geminivirus isolates by using their sequence information Recombination Detection Program (RDP) was utilized, which is based on a pair wise scanning approach. It usually runs under Windows 95/98/NT/XP/NISTA/7 and couples a high degree of analysis automation with an interactive and detailed graphical user interface ${ }^{15}$. Using various recombination detection method the conclusion of recombination studies are evaluated ${ }^{16,17}$. The recombination breakpoint could be identified by using Recombination detection program [RDP], GENECONV, Maximum-Chi, BOOTSCAN, CHIMAERA and 3SEQ methods. All these methods were implemented in RDP v.3.44 ${ }^{18}$.

\section{RESULTS AND DISCUSSION}

Begomovirus associated symptoms such as Leaf curl disease of A. sessilis (Fig. 1) was observed on several plants growing in the gardens of Lakshmangarh (Rajasthan) in

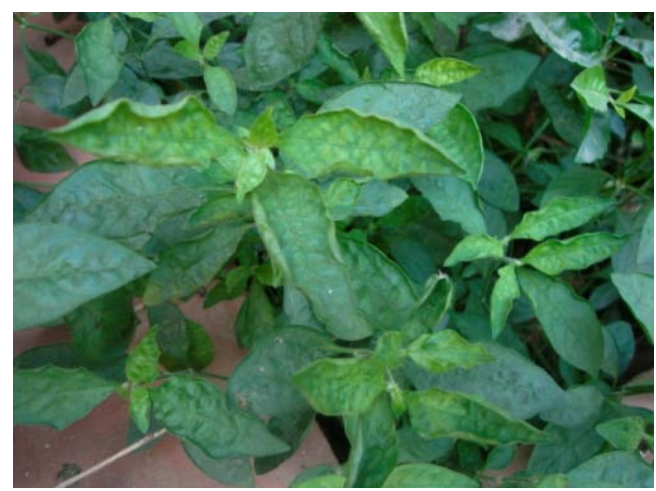

Fig. 1: Symptoms of leaf curl disease in Alternanthera sessilis

Dec 2011. The coordinates where infection found in A. sessilis and from where the plant sample was collected were Latitude: $27 \mathrm{~N}$ 80' 16.52" and Longitude: 75E 03' 47.76". Through PCR amplification product of the expected size (approx. $550 \mathrm{bp)}$ was produced from all symptomatic samples of $A$. sessilis but not from nonsymptomatic samples. BLAST analysis was conducted with Geminivirus sequences available in the GenBank database. The alignment process of begomoviral sequence reveals $98 \%$ identity with Tomato leaf curl Kerala virus isolate ToLCV (EU910141) and 97\% identity with Tomato leaf curl Kerala virus isolate ToLCV-K5 (EU910140). Phylogenetic analysis of coat protein gene isolated from A. sessilis (Fig. 2) was done by using MEGA 4.0 showing the relationship with other closely related viruses.

Recombination is a major mechanism in virus evolution, allowing viruses to evolve more quickly by providing immediate direct access to many more areas of a sequence space than are accessible by mutation alone. The maximum $\chi^{2}$ method is modification of the program MaxChi for identifying recombination breakpoints. Given an alignment MaxChi examines sequence pairs and seeks to identify recombination breakpoints by looking for significant differences in the proportions of variable and non-variable polymorphic alignment positions in adjacent regions of sequence. Although the maximum $\chi^{2}$ method performs best when only two parental sequences and a recombinant sequence are compared, it is possible to use the method to examine alignments of more than 3 sequences. The approximate $\mathrm{p}$-values of two peaks in MaxChi plot were $6.596 \times 10^{-04}$ and $5.844 \times 10^{-04}$ (Fig. 3).

Beginning breakpoint position was 140 in alignment and ending breakpoint position was 578 in alignment. According to MaxChi the major parent was DQ343284 (Tomato leaf curl virus from soybean coat protein gene, complete cds) and minor parent was DQ376039 (Papaya leaf curl virus isolate Kavitha coat protein gene, complete cds). MaxChi provides information on the 


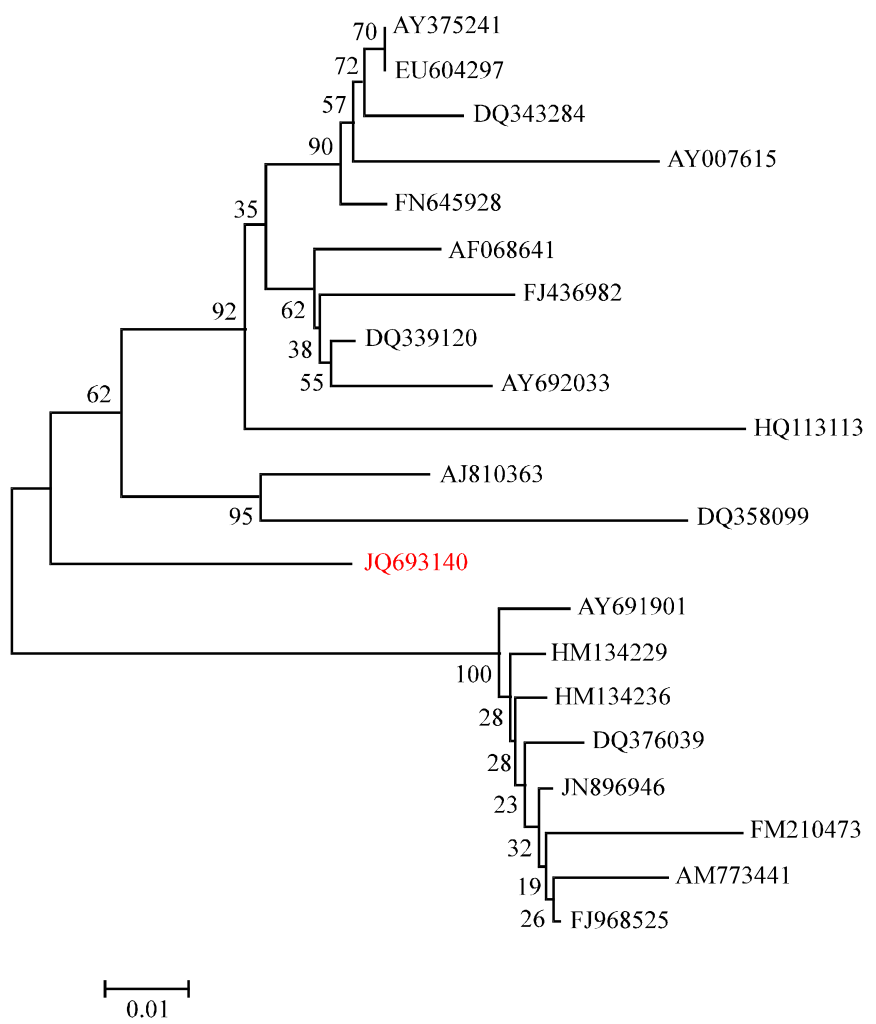

Fig. 2: Neighbor-Joining tree based on the partial sequence of coat protein gene (JQ693140), of the virus isolated from Alternanthera sessilis and other begomovirus sequences available in GenBank. The different begomoviruses used in the construction of phylogenetic tree were: Tomato leaf curl virus AV1 gene for coat protein, isolate 24 (AJ810363). Tomato leaf curl Karnataka virus-[tomato:Lucknow] precoat protein (AV2) and coat protein (AV1) genes, complete cds (AY375241). Tomato leaf curl Karnataka virus isolate Lucknow coat protein (AV1) gene, complete cds (EU604297). Whitefly-transmitted Indian begomovirus from Tagetes erecta coat protein (AV1) gene, complete cds (DQ339120). Tomato leaf curl virus from soybean coat protein gene, complete cds (DQ343284). Chilli leaf curl virus partial cp gene for coat protein, clone CHL1 (FM210473). Jatropha mosaic India virus-Chilli pepper coat protein gene, complete cds (HQ113113). Chilli leaf curl virus partial CP gene for coat protein, isolate midhills (AM773441). Papaya leaf curl virus isolate Kavitha coat protein gene, complete cds (DQ376039). Tomato leaf curl virus coat protein (AV1) gene, complete cds (AY691901). Pepper leaf curl virus coat protein (AV1) gene, partial cds; and nonfunctional replication enhancer protein (AC3) gene, partial sequence (FJ968525). Chilli leaf curl virus-Naj 3 [India:New Delhi: Papaya:2009] coat protein gene, complete cds (HM134236). Tomato geminivirus coat protein (AV1) gene, partial cds (AF068641). Tomato leaf curl virus-Panipat 7 [India:Panipat: Papaya:2008] coat protein gene, complete cds (HM134229). Chilli leaf curl virus [India:UP:Lucknow: Capsicum sp.11b:2011] coat protein (AV1) gene, complete cds (JN896946). Tomato leaf curl virus strain TNAU2 pre-coat protein (AV2) and coat protein (AV1) genes, complete cds (DQ358099). Tobacco leaf curl virus isolate TbLCV-Kar1 coat protein (AV1) gene, complete cds (AY007615). Tomato leaf curl Karnataka virus isolate Bahraich coat protein (AV1) gene, complete cds (FJ436982). Guar begomovirus JAK-2004 core region of coat protein (AV1) gene, partial sequence (AY692033). Tomato leaf curl Karnataka virus partial AV1 gene for coat protein, clone Cgc-PCR A1 (FN645928)

positions of potential breakpoints but does not give information on the extent of recombinant regions. The "scan triplets" setting used RDP3 making attempt to match potential breakpoints and that sequences between match breakpoints within a single recombinant region. Along with CHIMAERA, MaxChi also one of the most accurate breakpoint detection methods implemented in RDP3. 


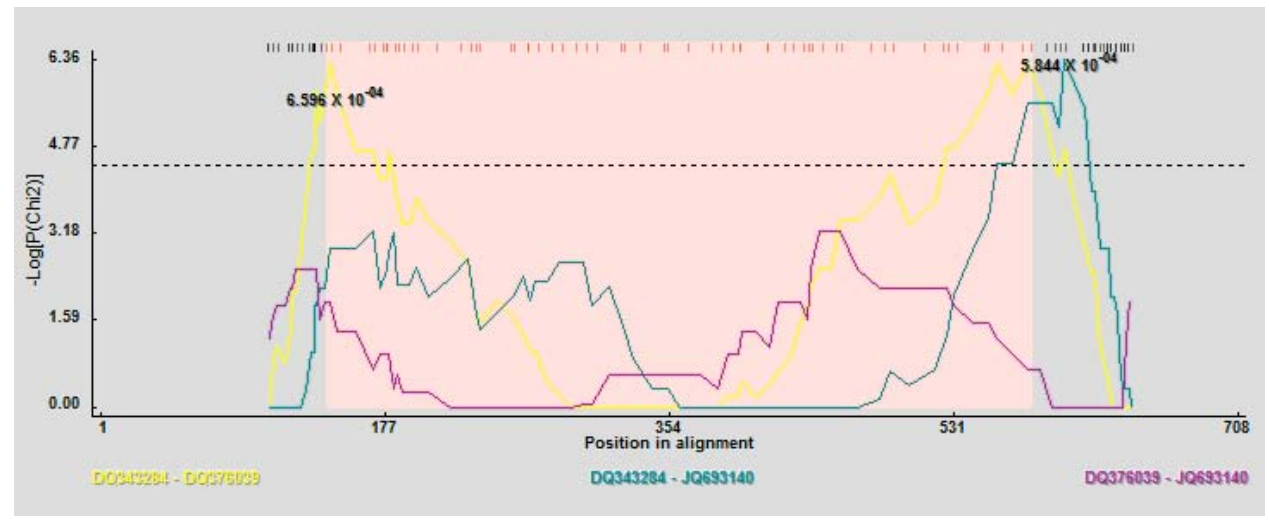

Fig. 3: An example of MaxChi plot for recombinant Alternanthera leaf curl virus coat protein-like gene, partial sequence (JQ693140). In this case the left and right bounds of the pink region indicate breakpoint positions

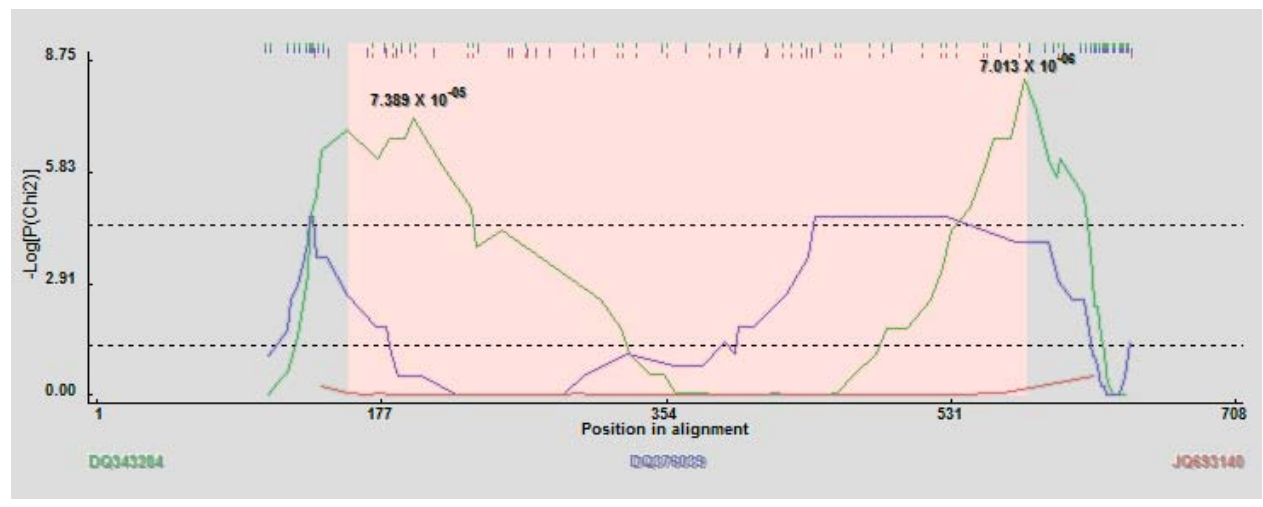

Fig. 4: An example of CHIMAERA plot. The left and right bounds of the pink region indicate breakpoint positions

CHIMAERA is David Posada's modification of Maynard Smith's maximum $\chi^{2}$ method $^{19}$. The differences between CHIMAERA and MaxChi are (1) the way in which polymorphic sites are chosen and (2) CHIMAERA can only be used to screen triplets. As with MaxChi, CHIMAERA provides information on the positions of potential breakpoints but does not give information on the extent of recombinant regions. RDP3 determines recombinant regions from $\chi^{2}$ peaks in exactly the same way as it does for MaxChi. Along with MaxChi, CHIMAERA is one of the most accurate breakpoint detection methods implemented in RDP3.

CHIMAERA Plot indicate as major parent as recombinant (DQ343284, green), minor parent as recombinant (DQ376039, blue) and recombinant as recombinant (purple). The approximate p-values of two peaks were $7.389 \times 10^{-05}$ and $7.013 \times 10^{-06}$. Uppermost red bares indicating positions of informative sites and region bounded by estimated breakpoint positions represented by dotted line (Fig. 4). The Chimaera beginning breakpoint position was 156 in alignment and ending breakpoint position was 577 in alignment. Beginning breakpoint probability was 2.594 E-03 and ending breakpoint probability was $2.364 \mathrm{E}-04$. The region probability (MC Uncorrected) was 5.273 E-09 and region probability (MC corrected) was 7.013 E-06.

Recombination positions in virus Alternanthera leaf curl virus (JQ693140) infecting A. sessilis were identified (Fig. 5). The schematic sequence display is where the results of automated recombination scans are presented and it is the part of the program that is used to drive the manual checking of automated analysis results. The coloured rectangles represent sequence fragments representing the recombinant (JQ693140), major parent (DQ343284) in brown colour and minor parent (DQ376039) in dark green colour.

The construction of Recombinant Region Count Matrix ${ }^{20,21}$ is an overview of the unique events detected in an automated recombination analysis and indicates how often different parts of the analysed sequences are 


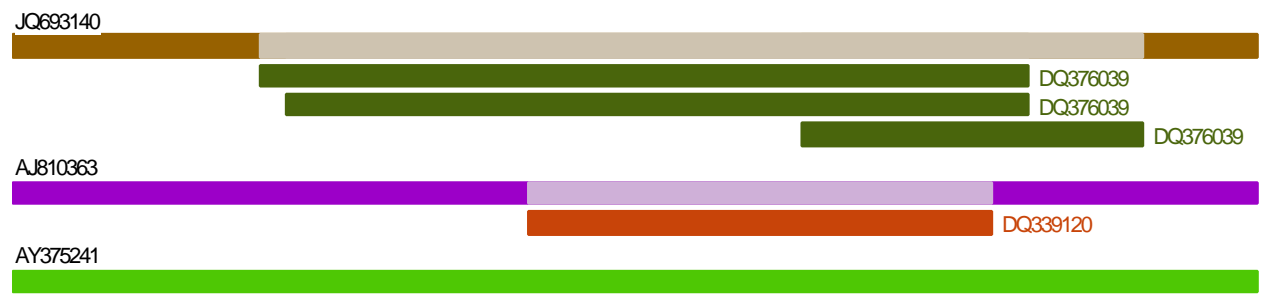

Fig. 5: The schematic sequence display

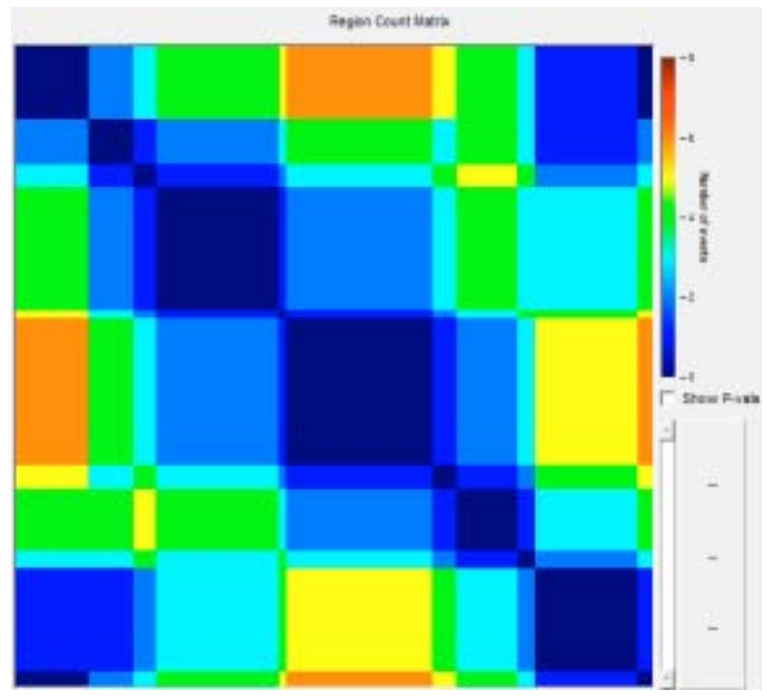

Fig. 6: Recombination Region Count Matrix of Unique Recombination Events Detected amongst coat protein Sequences of various Begomoviruses that were used during phylogenetic analysis. The shades displayed are a function of the number of times pairs of nucleotides (plotted on the $\mathrm{x}$ and $\mathrm{y}$-axis) are separated during the observed set of unique recombination events

separated from one another by recombination. Specifically, colours indicate the number of times recombination events have separated pairs of nucleotides (Fig. 6).

\section{CONCLUSION}

A. sessilis an ornamental plant is found to be infected with begomovirus, which was identified through PCR and BLAST analysis. Phylogenetic analysis of coat protein gene isolated from $A$. sessilis was done by using MEGA 4.0 showing the relationship with other closely related viruses. Based on the symptoms and sequence information, the Alternanthera leaf curl disease in India is associated with Tomato leaf curl Kerala virus. This relut suggested that Alternanthera sessilis is a new host of Tomato leaf curl Kerala virus and is a serious threat to other economically important crops and may contribute to the epidemiology of Tomato leaf curl Kerala virus diseases in India. Uses of computational recombination detection tools such as MaxChi and CHIMAERA implemented in RDP3 have demonstrated the evidence of recombination in a wide range of the available genome sequences of Begomovirus. Geminiviruses cause a variety of symptoms in host plant species and are spreading easily due to a high rate of recombination and pseudorecombination events that contribute in the evolution of new viral species. This study could be used to understand the role of recombination and pseudorecombination in evolution of new begomovirus species and genetic diversity.

\section{ACKNOWLEDGMENT}

The authors would like to acknowledge a vote of thanks to Department of Biotechnology (DBT project No. BT/PR13129/GBD/27/197/2009) and Department of Science and Technology (DST project no. SR/FT/LSo42/2009), India for their financial support. 


\section{REFERENCES}

1. Scher, J., 2004. Federal noxious weed disseminules of the US Center for plant health science and technology, plant protection and quarantine, animal and plant health inspection service. US Department of Agriculture, USA.

2. Naples, M.L., 2005. Weeds of rain fed lowland rice fields of Laos and Cambodia. M.Sc. Thesis, University of Leiden, The Netherlands.

3. Moffat, A.S., 1999. Plant pathology: Geminiviruses emerge as serious crop threat. Science, 286: 1835-1835.

4. Fauquet, C.M., D.M. Bisaro, R.W. Briddon, J.K. Brown and B.D. Harrison et al., 2003. Virology division news: Revision of taxonomic criteria for species demarcation in the family Geminiviridae and an updated list of begomovirus species. Arch. Virol., 148: 405-421.

5. Hanley-Bowdoin, L., S.B. Settlage, B.M. Orozco, S. Nagar and D. Robertson, 1999. Geminiviruses: Models for plant DNA replication, transcription and cell cycle regulation. Crit. Rev. Plant Sci., 18: 71-106.

6. Mansoor, S., R.W. Briddon, Y. Zafar and J. Stanley, 2003. Geminivirus disease complexes: An emerging threat. Trends Plant Sci., 8: 128-134.

7. Markham, P.G., S.L. Bedford and M.S. Pinner, 1994. The transmission of geminivirus by Bemisia tabaci. Pesticide Sci., 42: 123-128.

8. Stanley, J., D.M. Bisaro, R.W. Briddon, J.K. Brown and C.M. Fauquet et al, 2005. Geminiviridae. In: Virus Taxonomy, 8th Report of the ICTV, Fauquet, C.M., M.A. Mayo, J. Maniloff, U. Desselberger and L.A. Ball (Eds.). Elsevier/Academic Press, London, pp: 301-326.

9. Harrison, B.D. and D.J. Robinson, 1999. Natural genomic and antigenic variation in whiteflytransmitted Geminiviruses (Begomoviruses). Annu. Rev. Phytopathol., 37: 369-398.

10. Zhou, X., Y. Liu, L. Calvert, C. Munoz, G.W. OtimNape, D.J. Robinson and B.D. Harrison, 1997. Evidence that DNA-A of a Geminivirus associated with severe cassava mosaic disease in Uganda has arisen by interspecific recombination. J. Gen. Virol., 78: 2101-2111.
11. Manen, J.F., O. Sinitsyna, L. Aeschbach, A. Markov and A. Sinitsyn, 2005. A fully automatable enzymatic method for DNA extraction from plant tissues. BMC Plant Biol., Vol. 5, 10.1016/j.clon.2012.04.006

12. Hallan, V., 1998. Genomic organization of geminivirus causing leaf curl in tomato (Lycopersicon esculentum). Ph.D Thesis. University of Lucknow, Lucknow, India.

13. Marwal, A., A. Sahu, R. Prajapat, D.K. Choudhary, R.K. Gaur, 2012. First report of association of a begomovirus with the leaf curl disease of a common weed, Datura inoxia. Indian J. Virol., 23: 83-84.

14. Tamura, K., J. Dudley, M. Nei and S. Kumar, 2007. MEGA4: Molecular Evolutionary Genetics Analysis (MEGA) software version 4.0. Mol. Biol. Evol., 24: 1596-1599.

15. Marwal, A., R. Prajapat, A. Sahu and R.K. Gaur, 2012. In silico recombination analysis: A study for geminivirus host mobility. Asian J. Biol. Sci., 5: 1-8.

16. Posada, D. and K.A. Crandall, 2001. Evaluation of methods for detecting recombination from DNA sequences: Computer simulations. Proc. Nat. Acad. Sci., USA., 98: 13575-13762.

17. Posada, D., 2002. Evaluation of methods for detecting recombination from DNA sequences: Empirical data. Mol. Biol. Evol., 19: 708-717.

18. Martin, D.P., D. Posada, K.A. Crandall and C. Williamson, 2005. A modified Bootscan algorithm for automated identification of recombinant sequences and recombination breakpoints. AIDS Res. Hum. Retroviruses, 21: 98-102.

19. Smith, J.M., 1992. Analyzing the mosaic structure of genes. J. Mol. Evol., 34: 126-129.

20. Lefeuvre, P., J.M. Lett, B. Reynaud and D.P. Martin, 2007. Avoidance of protein fold disruption in natural virus recombinants. Publ. Lib. Sci. Pathog., 10.1371/journal.ppat.0030181

21. Lefeuvre, P., J.M. Lett, A. Varsani and D.P. Martin, 2009. Widely conserved recombination patterns among single-stranded DNA viruses. J. Virol., 83: 2697-2707. 